\title{
Feeder Reconfiguration in Unbalanced Distribution System with Wind and Solar Generation using Ant Lion Optimization
}

\author{
Surender Reddy Salkuti \\ Department of Railroad and Electrical Engineering \\ Woosong University, Daejeon \\ South Korea
}

\begin{abstract}
This paper proposes an approach for the distribution system (DS) feeder reconfiguration (FRC) of balanced and unbalanced networks by minimizing the total cost of operation. Network reconfiguration is a feasible technique for system performance enhancement in low voltage distribution systems. In this work, wind and solar photovoltaic (PV) units are selected as distributed energy resources (DERs) and they are considered in the proposed FRC approach. The uncertainties related to DERs are modeled using probability analysis. In most cases, the distribution system is an unbalanced system and the 3phase transformers play a vital role as they have different configurations. This paper proposes efficient power flow models for the unbalanced distribution systems with various 3-phase transformer configurations. The proposed FRC approach has been solved by using the evolutionary algorithm based Ant Lion Optimization (ALO), and it has been implemented on 17 bus test system considering the balanced and unbalanced distribution systems with and without RESs.
\end{abstract}

Keywords-Distributed energy resources; evolutionary algorithms; feeder reconfiguration; operational cost; optimization algorithms; three-phase transformers

\section{INTRODUCTION}

Electrical energy is considered an important source for any country's economic growth. Integration of various renewable energy sources (RESs) into electrical power networks is increasing due to the importance of environmental safety and to make less dependency on the gradual depletion of fossil fuels. Conventional energy sources mainly depend on fossil fuels for power generation [1]. Large-scale utilization of fossil fuels causes resource depletion as well as global warming. Among all the available RESs [2], wind and solar photovoltaic (PV) energy systems have become popular. However, largescale penetration of RESs can lead to various challenges, as these sources are intermittent and variable. Optimal allocation and operation of these RESs in the distribution network lead to a decrease in power losses, enhancement in voltage profile, and system reliability.

\section{A. Related Works}

An optimization approach for the restoration of an unbalanced distribution system after large-scale outages with DERs has been proposed in [3]. A methodology for the feeder reconfiguration (FRC) for three-phase unbalanced distribution systems (DSs) with DERs at various bus locations and sizes of
DG units using nonlinear programming and sensitivity analysis is proposed in [4]. The author in [5] proposes a distributed secondary control approach for the DGs integrated with grid-integrated inverters in unbalanced dynamic microgrids (MGs). A heuristic-based method is proposed in [6] to simplify the graph of the radial distribution system (RDS) to reduce the computational complexity by optimizing the system power losses, switching operations, and the out-ofservice load demands. A chaotic stochastic fractal search technique for solving the FRC problem to reduce system losses and to enhance the voltage profile in the distribution systems is proposed in [7]. A simple FRC technique for the balanced and unbalanced RDSs is proposed in [8]. The solution of multi-objective-based FRC with optimal capacitor allocation problem with multiple time intervals with DERs is proposed in [9].

An analytical methodology for the FRC with DG hosting to minimize the system losses in the RDSs is proposed in [10]. A systematic overview of distribution FRC approaches for mitigating distribution systems' unbalance is described in [11]. A dynamic FRC methodology for a 3-phase unbalanced RDS is formulated as a problem of mixed-integer linear programming has been proposed in [12]. The author in [13] proposes a new FRC approach in unbalanced and balanced distribution systems to simultaneously optimize the allocation of distributed generation (DG) and reconfiguration. A scenario-based approach for addressing the uncertainty in solar irradiance, wind speed, and load demand is proposed in [14]. An integrated approach for simultaneous optimal allocation of inverter-based DGs, passive filters, along with distribution FRC in unbalanced and balanced microgrids (MGs) is proposed in [15]. The author in [16] proposes a dynamic distribution FRC approach over multiple time intervals operation cost, energy not served, and power loss objectives.

From the above literature, it is clear that the load flow studies and FRC studies are performed for the balanced distribution system, however, in actual practice they are unbalanced. In this paper, an augmented $\pi$ model-based distribution transformer has been implemented by including the fictitious voltage-dependent current injection sources on primary and secondary sides to model various connections of distribution transformers. The remainder of this article is organized as follows: Section II describes the distribution load 
flow with different transformer connections. Section III is devoted to the power output and uncertainty modeling of RERs. Section IV discusses the problem formulation of the proposed optimal FRC approach. A brief description of the ant lion optimization (ALO) algorithm has been presented in Section V. Section VI presents the simulation results and discussions of the three-phase balanced and unbalanced distribution systems with and without considering the RESs. Finally, conclusions are made in Section VII.

\section{Distribution LOAD FlOW WITH TRANSFORMER MODELING}

Generally, the distribution systems are unbalanced. Hence, a three-phase representation of distribution system components is necessary. The transformer is one of the most important components in the distribution network, and the impact of its winding connection is significant. A three-phase transformer is represented by two blocks as depicted in Fig. 1 [17-18]. The series block shows the winding connection and leakage impedance and the shunt block on the secondary side represents the active power and reactive power losses in the core of the transformer, as a function of voltage. Since the series block affects the core losses, the main focus is on the series block and the shunt block is treated as the load at the secondary of the transformer.

Several approaches have been developed to model various winding connections of the three-phase transformer. Fictitious current source injections along with a series branch are used to decoupled primary and secondary sides. The models involving primary and secondary voltages are dependent on the current injections and series branch, are different for different types of connections. However, this technique slows down the convergence of the forward/backward load flow method. By using the nodal admittance matrix $\left(Y_{T}\right)$, the voltage and current relationship of the transformer is represented as,

$\left[\begin{array}{c}\mathrm{I}_{\mathrm{p}} \\ \mathrm{I}_{s}\end{array}\right]=\left[\begin{array}{cc}\mathrm{Y}_{p p} & \mathrm{Y}_{p s} \\ \mathrm{Y}_{s p} & \mathrm{Y}_{s s}\end{array}\right]\left[\begin{array}{c}\mathrm{V}_{p} \\ \mathrm{~V}_{s}\end{array}\right]=\left[\begin{array}{c}\mathrm{Y}_{p p} \mathrm{~V}_{p}+\mathrm{Y}_{p s} \mathrm{~V}_{s} \\ \mathrm{Y}_{s p} \mathrm{~V}_{p}+\mathrm{Y}_{s s} \mathrm{~V}_{s}\end{array}\right]$

Where the matrix $Y_{T}$ is divided into the four $(3 \times 3)$ submatrices $\left(\mathrm{Y}_{p p}, Y_{p s}, Y_{s p}\right.$ and $\left.Y_{s s}\right)$ as shown in equation (1) [17]. Table I presents the sub-matrices of $Y_{T}$, for the common stepup and step-down transformer configurations.
In table I,

$$
\begin{gathered}
Y_{\mathrm{I}}=\left[\begin{array}{lll}
1 & 0 & 0 \\
0 & 1 & 0 \\
0 & 0 & 1
\end{array}\right] y_{t}, Y_{\mathrm{II}}=\frac{1}{3}\left[\begin{array}{ccc}
2 & -1 & -1 \\
-1 & 2 & -1 \\
-1 & -1 & 2
\end{array}\right] y_{t}, Y_{\mathrm{III}} \\
=\frac{1}{\sqrt{3}}\left[\begin{array}{ccc}
-1 & 1 & 0 \\
0 & -1 & 1 \\
1 & 0 & -1
\end{array}\right] y_{t}
\end{gathered}
$$

\section{A. $Y_{g}-\Delta$ Step-Down Transformer}

The augmented $\pi$-model for the $Y_{g}-\Delta$ step-down transformer is described next:

By substituting $\mathrm{Y}_{p p}, \mathrm{Y}_{p s}, \mathrm{Y}_{s p}$ and $\mathrm{Y}_{s s}$ values from Table I, then the equation (1) becomes [18],

$I_{p}=Y_{I} V_{p}+Y_{I I I} V_{S}$

$I_{s}=Y_{I I}^{T} V_{p}+Y_{I I} V_{s}$

For developing a 3-phase transformer model, equations (2) and (3) is modified by voltage-dependent injections, and they are expressed as,

$I_{p}=Y_{I} V_{p}+Y_{I I I} V_{s}+X V_{s}-X V_{s}$

$I_{s}=Y_{I I I}^{T} V_{p}+Y_{I I} V_{s}+X^{T} V_{p}-X^{T} V_{p}$

By selecting $X=-Y_{I I I}-Y_{I}, X^{T}=-Y_{I I I}^{T}-Y_{I}^{T}$, the above equations become,

$\left[\begin{array}{c}\mathrm{I}_{p}^{\prime} \\ \mathrm{I}_{s}^{\prime}\end{array}\right]=\left[\begin{array}{c}I_{p}+X V_{s} \\ I_{s}+X^{T} V_{p}\end{array}\right]=\left[\begin{array}{cc}\mathrm{Y}_{\mathrm{I}} & -\mathrm{Y}_{\mathrm{I}} \\ -\mathrm{Y}_{\mathrm{I}}^{\mathrm{T}} & \mathrm{Y}_{\mathrm{II}}\end{array}\right]\left[\begin{array}{c}\mathrm{V}_{p} \\ \mathrm{~V}_{s}\end{array}\right]$

Here $Y_{I}=Y_{I}^{T}$ and inverse of $Y_{I}$ exists. In the equations (4) and (5), the left-hand side term corresponds to the fictitious current injections. The right-hand side term in equations (4) and (5) represents the $\pi$-model, and it is presented in Fig. 2.

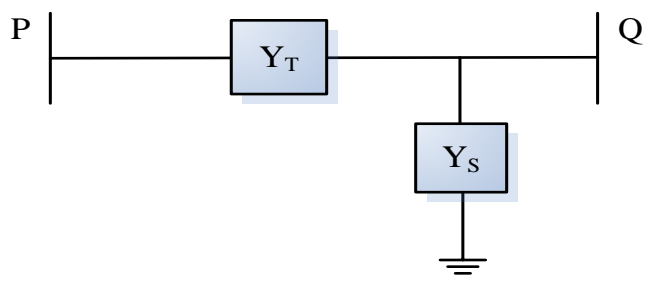

Fig. 1. Three-Phase Transformer Model.

\begin{tabular}{|c|c|c|c|c|c|c|c|c|c|}
\hline \multirow{2}{*}{ Primary } & \multirow{2}{*}{ Secondary } & \multicolumn{4}{|c|}{ Step-down transformer connections } & \multicolumn{4}{|c|}{ Step-up transformer connections } \\
\hline & & $Y_{p p}$ & $Y_{s s}$ & $Y_{p s}$ & $Y_{s p}$ & $Y_{p p}$ & $Y_{s s}$ & $Y_{p s}$ & $Y_{s p}$ \\
\hline$Y_{g}$ & $Y_{g}$ & $Y_{I}$ & $Y_{I}$ & $-Y_{I}$ & $-Y_{I}$ & $Y_{I}$ & $Y_{I}$ & $-Y_{I}$ & $-Y_{I}$ \\
\hline$Y_{g}$ & $Y$ & $Y_{I I}$ & $Y_{I I}$ & $-Y_{I I}$ & $-Y_{I I}$ & $Y_{I I}$ & $Y_{I I}$ & $-Y_{I I}$ & $-Y_{I I}$ \\
\hline$Y_{g}$ & $\Delta$ & $Y_{I}$ & $Y_{I I}$ & $Y_{I I I}$ & $Y_{I I I}^{T}$ & $Y_{I}$ & $Y_{I I}$ & $Y_{I I I}^{T}$ & $Y_{I I I}$ \\
\hline$Y$ & $Y_{g}$ & $Y_{I I}$ & $Y_{I I}$ & $-Y_{I I}$ & $-Y_{I I}$ & $Y_{I I}$ & $Y_{I I}$ & $-Y_{I I}$ & $-Y_{I}$ \\
\hline$Y$ & $Y$ & $Y_{I I}$ & $Y_{I I}$ & $-Y_{I I}$ & $-Y_{I I}$ & $Y_{I I}$ & $Y_{I I}$ & $-Y_{I I}$ & $-Y_{I}$ \\
\hline$Y$ & $\Delta$ & $Y_{I I}$ & $Y_{I I}$ & $Y_{I I I}$ & $Y_{I I I}^{T}$ & $Y_{I I}$ & $Y_{I I}$ & $Y_{I I I}^{T}$ & $Y_{I I I}$ \\
\hline$\Delta$ & $Y_{g}$ & $Y_{I I}$ & $Y_{I}$ & $Y_{I I I}$ & $Y_{I I I}^{T}$ & $Y_{I I}$ & $Y_{I}$ & $Y_{I I I}^{T}$ & $Y_{I I I}$ \\
\hline$\Delta$ & $Y$ & $Y_{I I}$ & $Y_{I I}$ & $Y_{I I I}$ & $Y_{I I I}^{T}$ & $Y_{I I}$ & $Y_{I I}$ & $Y_{I I I}^{T}$ & $Y_{I I I}$ \\
\hline$\Delta$ & $\Delta$ & $Y_{I I}$ & $Y_{I I}$ & $-Y_{I I}$ & $-Y_{I I}$ & $Y_{I I}$ & $Y_{I I}$ & $-Y_{I I}$ & $-Y_{I}$ \\
\hline
\end{tabular}

TABLE I. SUBMATRICES FOR THE COMMON STEP-DOWN AND STEP-UP TRANSFORMER CONFIGURATIONS 


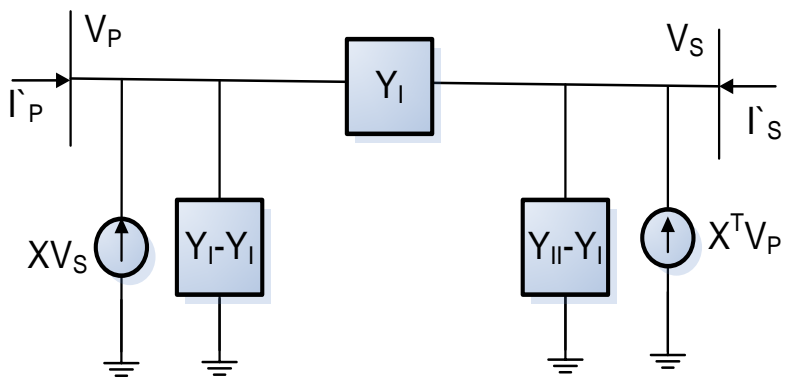

Fig. 2. $\pi$-Model of Yg- $\Delta$ Step-Down Transformer with Fictitious Currents.

B. Step-by-Step Approach for the Load Flow with Transformers

Step 1: Read test system data, and initialize the voltages at all buses in the distribution network.

Step 2: Select X based on the transformer configuration.

Step 3: Determine the fictitious voltage-dependent current injections for the transformer.

Step 4: Form the BIBC and BCBV matrices.

Step 5: Run the load flow.

Step 6: Check for the convergence criteria. If satisfied, then STOP. Otherwise, go to Step 3.

\section{MODELING OF WIND AND SOLAR PV POWER GENERATION}

The uncertain nature of wind speed (v) and solar irradiance (G) can be modeled by using the probability analysis/probability distribution function (PDF).

\section{A. Modeling of Wind Power Generation}

The amount of power output from WEG will depend on the location and the wind speed, and it can be expressed as [19],

$P_{W}=\left\{\begin{array}{c}0 \text { for } v<v_{\text {cin }} \text { and } v>v_{\text {cout }} \\ \left(\frac{P_{W}^{r}}{v_{r}^{3}-v_{\text {cin }}^{3}}\right) v^{3}+\left(\frac{v_{\text {cin }}^{3}}{v_{r}^{3}-v_{\text {cin }}^{3}}\right) P_{W}^{r} \text { for } v_{\text {cin }} \leq v \leq v_{r} \\ P_{W}^{r} \text { for } v_{r} \leq v \leq v_{\text {cout }}\end{array}\right.$

Here, the Weibull PDF is used to model the wind power output and it can be represented by [20],

$f_{p}\left(P_{W}\right)=$

$\frac{k\left(v_{r}-v_{\text {cin }}\right)}{c^{k} P_{W}^{r}}\left[v_{\text {cin }}+\right.$

$\left.\frac{P_{W}}{P_{W}^{r}}\left(v_{r}-v_{\operatorname{cin}}\right)^{k-1}\right] \exp \left[-\left[\frac{v_{\operatorname{cin}}+\frac{P_{W}}{P_{W}^{r}}\left(v_{r}-v_{\operatorname{cin}}\right)}{c}\right]^{k}\right]$

\section{B. Modeling of Solar PV Power Generation}

Power output from solar PV unit depends on solar insolation and ambient temperature at a particular location and it can be expressed as [20],

$P_{P V}=\left(N_{P V} \times V \times I \times F F\right)$
The voltage-current (V-I) characteristics of the solar PV module concerning solar insolation (G) and ambient temperature $\left(T_{A}\right)$ are expressed as,

$V=V_{o c}-\left(K_{V} \times T_{c}\right)$

$I=G\left[I_{s c}+K_{I}\left(T_{c}-25\right)\right]$

$T_{C}=T_{A}+G\left(\frac{N_{O T}-20}{0.8}\right)$

$F F=\frac{V_{M P P} I_{M P P}}{V_{O C}{ }^{I} S C}$

In this paper, the bimodal distribution function is used to model the solar PV power output. Here, the Weibull PDF is used to model the power output. This can be expressed as [20, 21],

$f(G)=$

$\omega\left(\frac{k_{1}}{c_{1}}\right)\left(\frac{G}{c_{1}}\right)^{k_{1}-1} e^{-\left(\frac{G}{c_{1}}\right)^{k_{1}}}+(1-\omega)\left(\frac{k_{2}}{c_{2}}\right)\left(\frac{G}{c_{2}}\right)^{k_{2}-1} e^{-\left(\frac{G}{c_{2}}\right)^{k_{2}}}$

$k_{1}, k_{2}$ are shape factors, and $c_{1}, c_{2}$ are scale factors, respectively.

\section{Optimal FEeder RECONFIGURATION (FRC): Problem FORMULATION}

FRC is an important tool to be used in the operation of the distribution network at an optimum operating cost and to enhance the system's security/reliability. FRC refers to varying the topology of feeders by opening and/or closing the tie and sectionalizing switches. It is used to minimize the power losses and to relieve overload in the feeders. The major objective of the proposed smart distribution network FRC is to find an optimal set of switches that need to be opened and closed by minimizing the total operating cost (TOC) of the system. This objective can be expressed as [22-24]:

Minimize,

TOC $=\sum_{i=1}^{N_{F}}\left(C_{i} P_{i}\right)+\sum_{j=1}^{N_{W}}\left(C_{W j} P_{W j}\right)+\sum_{k=1}^{N_{S}}\left(C_{P V k} P_{P V k}\right)$

The above equation is solved subjected to the following constraints.

\section{A. Constraints}

The proposed FRC optimization problem must satisfy the following constraints, and they are presented next:

1) Equality constraints: These constraints refer to the power balancing in the distribution system, and it can be expressed as [25]:

$\sum_{i=1}^{N_{F}}\left(P_{i}\right)+\sum_{j=1}^{N_{W}}\left(P_{W j}\right)+\sum_{k=1}^{N_{S}}\left(P_{P V k}\right)=P_{D}$

2) Inequality constraints: The power constraint on feeders can be expressed as [26]:

$P_{i} \leq P_{i}^{\max } i=1,2, \ldots, N_{F}$

Power output from WEG can be limited by [27],

$P_{W j} \leq P_{W j}^{\max } j=1,2, \ldots, N_{W}$ 
Power output from solar PV unit can be limited by,

$P_{P V k} \leq P_{P V k}^{\max } k=1,2, \ldots, N_{P V}$

Voltage at each bus can be limited by,

$V_{b}^{\min } \leq V_{b} \leq V_{b}^{\max } b=1,2, \ldots, N_{B}$

Current in each feeder is limited by [28],

$\left|I_{l}\right| \leq I_{l}^{\max } l=1,2, \ldots, N_{l}$

\section{FRC USING ANT LION OptimizATION (ALO) ALGORITHM}

Generally, the DSs are unbalanced, and hence, three-phase representation of DS components is necessary. There are several works on load flows and FRC of balanced DSs. However, in actual practice the DSs are unbalanced. Therefore, in this section an unbalanced FRC approach for the total operating cost minimization objective is optimized by using the ALO algorithm. Here, it is important to consider the effect of three-phase transformer model as the configuration affects the system performance. As the FRC is a complex non-linear optimization problem and it can be solved by using various meta-heuristic algorithms. In the past several deterministic approaches have been used for solving this FRC problem. However, in recent years, various evolutionary-based optimization algorithms are found to be performing well for solving these problems.

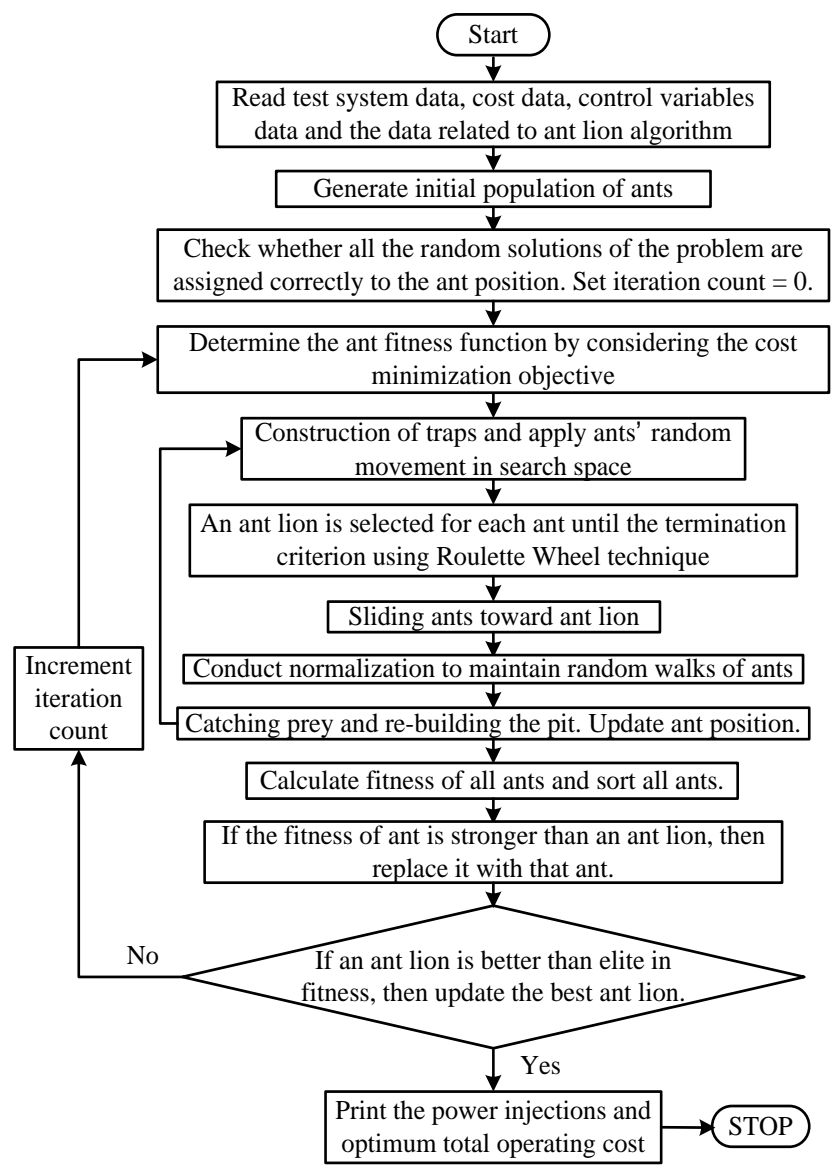

Fig. 3. Flowchart for FRC in RDS for Total Operating Cost Minimization using ALO Algorithm.
ALO is a meta-heuristic-based technique and it considers the interaction between the ants and ant lions in our nature [29]. In this ALO technique, two important stages are involved, and they are the larvae stage (i.e., hunting prey) and adult stage (i.e., reproduction) [30]. The flow chart of ALO for solving the proposed smart distribution network FRC has been depicted in Fig. 3. Initially, the data related to the test system and ant lion algorithm is read for solving the proposed FRC problem. The proposed ant lion algorithm includes various stages such as determination of fitness, construction of traps, catching prey, re-building the pit, and they are depicted in Fig. 3.

\section{SiMUlation RESUlTS AND DisCUSSION}

The proposed feeder reconfiguration (FRC) approach has been applied for 17 bus balanced and unbalanced distribution systems (DSs) [17]. This DS has 17 buses, 3 feeders, 19 branches, 3 tie-switches, and the base MVA is 100 [18]. Transformer (115 kV/13.2 kV) with $\Delta-Y_{g}$ is connected between buses 1 and 2, 1 and 3, and 1 and 4 . The leakage impedance of these transformers is $(0.01+j 0.05)$ p.u. Power limits in the feeders of phases R, Y, and B are 14.1 MW, 18.1 $\mathrm{MW}$, and 1.3 MW, respectively. The single line diagram (SLD) of this 17 bus test system has been depicted in Fig. 4. In this system, a wind farm is placed at bus number 14 , and a solar PV unit is placed at bus number 9. As mentioned earlier, Ant Lion Optimization (ALO) technique is used to solve the proposed FRC problem with and without RESs. Three feeders are coming from a single substation and they are connected through the 3-three phase transformers.

Rated capacities of WEG and solar PV units considered in this work are $2 \mathrm{MW}$. For the WEG, it is considered that the rated wind speed is $12 \mathrm{~m} / \mathrm{s}$, cut-in speed is $3 \mathrm{~m} / \mathrm{s}$, and cut-out speed is $25 \mathrm{~m} / \mathrm{s}$. For the solar PV unit, the maximum power point current $\left(I_{M P P}\right)$ is $7.76 \mathrm{~A}$, maximum power point voltage $\left(V_{M P P}\right)$ is $28.36 \mathrm{~V}$, the nominal operating temperature of the cell $\left(N_{O T}\right)$ is $43^{\circ} \mathrm{C}$, short circuit current $\left(I_{S C}\right)$ is $8.38 \mathrm{~A}$, opencircuit voltage $\left(V_{O C}\right)$ is $36.96 \mathrm{~V}$, temperature coefficient of voltage $\left(K_{V}\right)$ is $0.1278 \mathrm{~V} /{ }^{\circ} \mathrm{C}$, and the temperature coefficient of current $\left(K_{I}\right)$ is $0.00545 \mathrm{~A} /{ }^{\circ} \mathrm{C}$.

In this paper, two different case studies are simulated on 17 bus distribution system, and they are:

- Case Study 1: Feeder reconfiguration (FRC) in a balanced distribution system with and without renewable energy sources (RESs).

- Case Study 2: FRC in unbalanced distribution system with and without RESs.

\section{A. Simulation Results for Case Study 1}

As mentioned earlier, in this case, a balanced distribution system is considered. The active and reactive power demands in the balanced system are 86.10 MW and 51.90 MVAr, respectively. Here, the total operating cost (TOC) minimization objective is optimized with and without considering the RESs in the 17 bus balanced system. Table II presents the scheduled powers from the feeders and RESs for the 3-phase balanced system with and without RESs. Without considering the RESs, the optimum TOC obtained by using 
the ALO algorithm is $1895 \mathrm{MU} / \mathrm{MWh}$. In this case, the obtained active and reactive power losses are 3.02 MW and 4.12 MVAr, respectively.

In this case, the obtained opened lines for the FRC are between buses 5-8 (line number 7), 5-9 (line number 9), and 611 (line number 12). Fig. 6 depicts the final topology/after the FRC. The obtained voltage profile for Case Study 1 without RESs has been depicted in Fig. 6. The minimum voltages obtained in phases R, Y, and B are 0.9352 p.u., 0.9352 p.u., and 0.9352 p.u., respectively.
Table II also presents the FRC results considering the wind and solar PV units at buses 14 and 9, respectively. The TOC obtained, in this case, is $1870.358 \mathrm{MU} / \mathrm{MWh}$, which is less compared to without considering the RESs. The FRC/opened lines, in this case, are the same as the case without RESs (this topology is shown in Fig. 5). The voltage profile obtained in this case by considering the RESs has been depicted in Fig. 7. The minimum voltages obtained in $\mathrm{R}, \mathrm{Y}$, and $\mathrm{B}$ phases are 0.9506 p.u., 0.9506 p.u., and 0.9506 p.u., respectively.

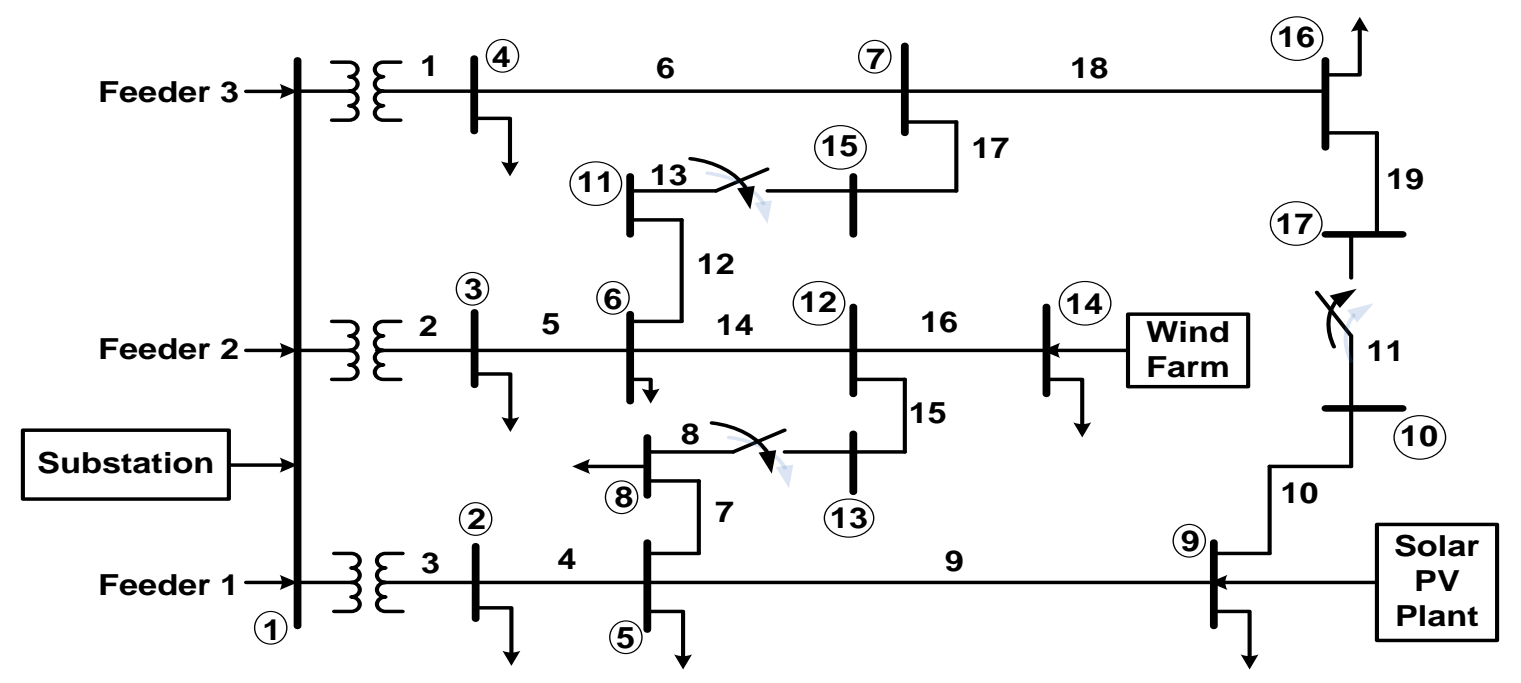

Fig. 4. Single Line Diagram (SLD) of 17 Bus Distribution System.

TABLE II. Scheduled Powers from Feeders and RESs for 3 Phase Balanced Distribution System (CASE Study 1)

\begin{tabular}{|l|l|l|l|l|}
\hline \multirow{2}{*}{ Balanced distribution system } & \multicolumn{2}{|l|}{ Without renewable power generation } & \multicolumn{2}{l|}{ With renewable power generation } \\
\cline { 2 - 5 } & Active Power (MW) & Reactive Power (MVAr) & Active Power (MW) & Reactive Power (MVAr) \\
\hline Feeder 1 & 6.04 & 4.82 & 4.77 & 2.02 \\
\hline Feeder 2 & 53.56 & 30.91 & 51.42 & 29.54 \\
\hline Feeder 3 & 29.52 & 20.29 & 26.24 & 19.85 \\
\hline Total generation & 89.12 & 56.02 & 88.75 & 55.21 \\
\hline Active power from WEG & ----- & 1.81 & 1.72 \\
\hline Active power from solar PV & ---- & 86.10 MW \\
\hline Active power demand & 86.10 MW & 51.90 MVAr \\
\hline Reactive power demand & 51.90 MVAr & 2.79 \\
\hline Active power loss & 3.02 MW & 3.80 \\
\hline Reactive power loss & 4.12 MVAr & $\mathbf{1 8 7 0 . 3 5 8}$ \\
\hline Total operating cost (MU/MWh) & $\mathbf{1 8 9 5 . 4 8 6}$ & $\mathbf{5 - 8 , 5 - 9 , 6 - 1 1}$ \\
\hline Opened lines between the buses & $\mathbf{5 - 8 , 5 - 9 , 6 - 1 1}$ & 0.9506 at bus 15 \\
\hline Minimum voltage in phase R (in p.u.) & 0.9352 at bus 15 & 0.9506 at bus 15 \\
\hline Minimum voltage in phase Y (in p.u.) & 0.9352 at bus 15 & 0.9506 at bus 15 \\
\hline Minimum voltage in phase B (in p.u.) & 0.9352 at bus 15 & \\
\hline
\end{tabular}




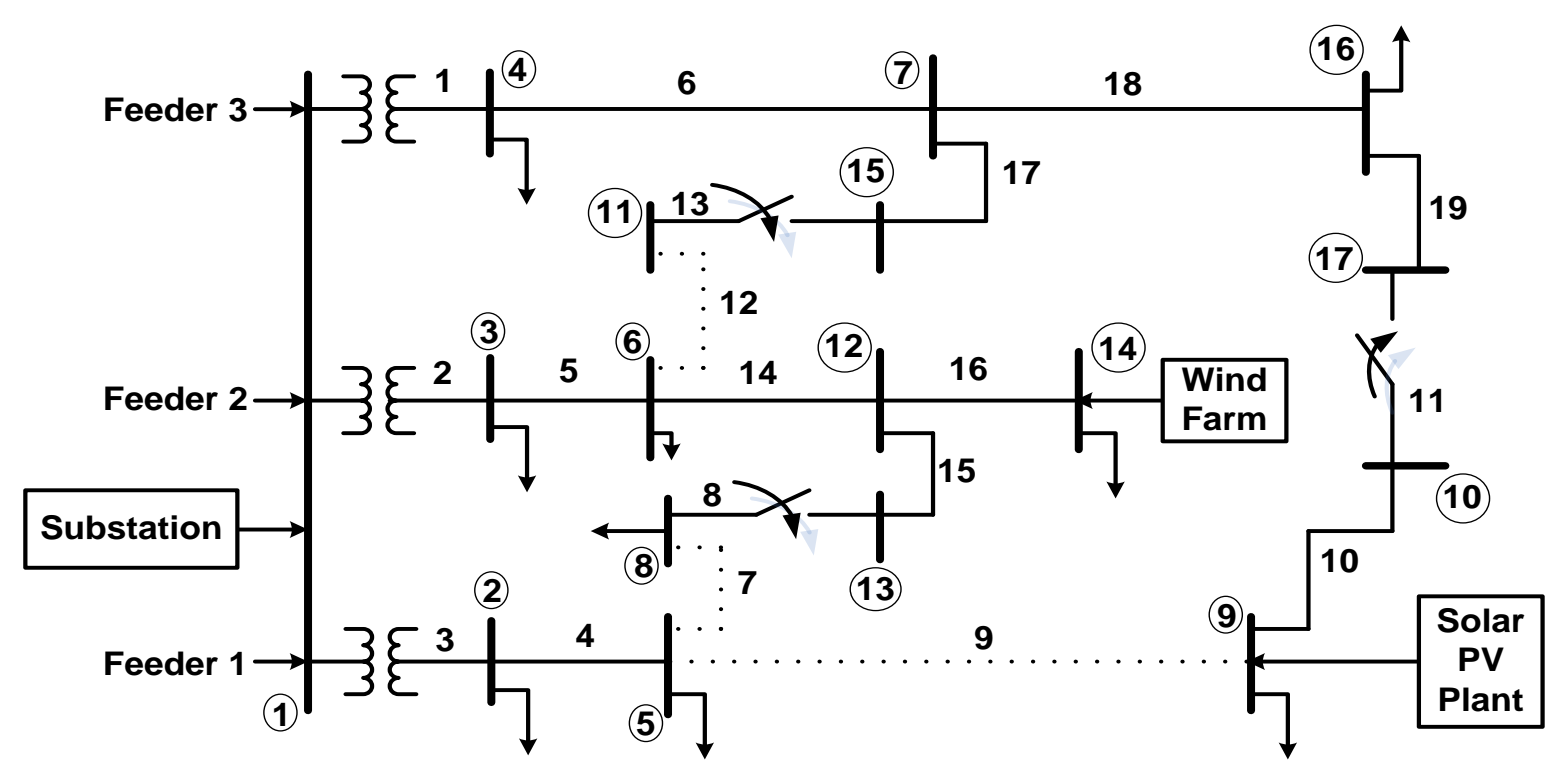

Fig. 5. SLD of 17 Bus System after the FRC for Case Study 1.

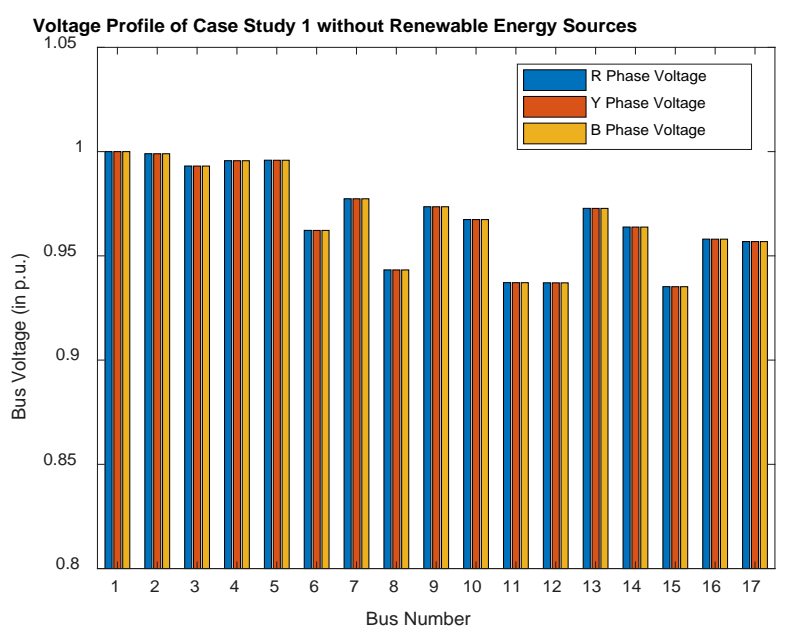

Fig. 6. Voltage Profile of Case Study 1 without Renewable Power Generation.

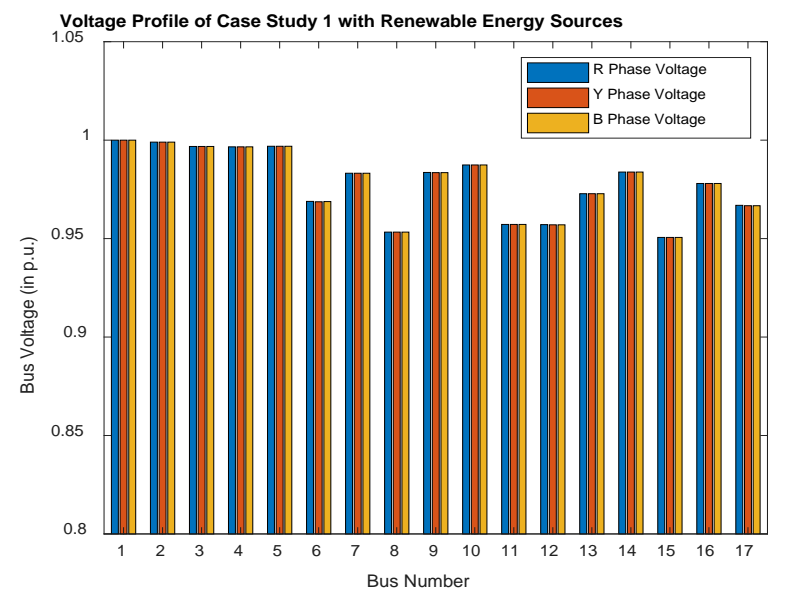

Fig. 7. Voltage Profile of Case Study 1 with Renewable Power Generation.

\section{B. Simulation Results for Case Study 2}

In this case study, an unbalanced distribution system with and without RESs is considered. The active and reactive power demands, in this case, are 86.961 MW and 52.419 MVAr, respectively. Here, the TOC minimization objective is optimized with and without considering the RESs in the 17 bus balanced system. Table III presents the scheduled powers from the feeders and RESs for Case Study 2. Without considering the RESs, the optimum TOC obtained by using the ALO algorithm is $1958.351 \mathrm{MU} / \mathrm{MWh}$. In this case, the obtained active and reactive power losses are $3.464 \mathrm{MW}$ and 0.892 MVAr, respectively.

In this case, the obtained opened lines for the FRC are between buses 5-9 (line number 9), 6-11 (line number 12), and 8-13 (line number 8). Fig. 8 depicts the final topology/after the FRC. The obtained voltage profile for Case Study 2 without RESs has been depicted in Fig. 9. The minimum voltages obtained in phases R, Y, and B are 0.9495 p.u., 0.9488 p.u., and 0.9474 p.u., respectively.

Table III also presents the FRC results considering the wind and solar PV units at buses 14 and 9, respectively. The TOC obtained, in this case, is $1926.247 \mathrm{MU} / \mathrm{MWh}$, which is less compared to without considering the RESs. The FRC/opened lines, in this case, are the same as the case without RESs (this topology is shown in Fig. 8). The voltage profile obtained in this case by considering the RESs has been depicted in Fig. 10. The minimum voltages obtained in R, Y, and B phases are 0.9657 p.u., 0.9641 p.u., and 0.9628 p.u., respectively.

From the above simulation results, it can be observed that the FRC topology obtained for the unbalanced DS is different from the balanced DS. However, the topology is the same for the cases with and without RESs. And also, the TOC obtained with RESs is less than the TOC obtained without the RESs. The nomenclature used in this work is presented in Table IV. 


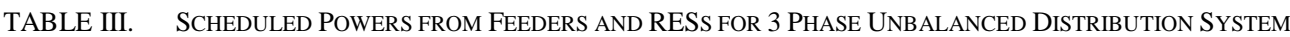

\begin{tabular}{|c|c|c|c|c|}
\hline \multirow{2}{*}{ Unbalanced distribution system } & \multicolumn{2}{|c|}{ Without renewable power generation } & \multicolumn{2}{|c|}{ With renewable power generation } \\
\hline & Active Power (MW) & Reactive Power (MVAr) & Active Power (MW) & Reactive Power (MVAr) \\
\hline Feeder 1 & 15.112 & 9.513 & 12.24 & 9.563 \\
\hline Feeder 2 & 45.001 & 24.053 & 43.287 & 42.157 \\
\hline Feeder 3 & 30.312 & 19.745 & 27.86 & 19.548 \\
\hline Total generation & 90.425 & 53.311 & 90.012 & 52.968 \\
\hline Active power from WEG & \multicolumn{2}{|l|}{----- } & \multicolumn{2}{|l|}{1.85} \\
\hline Active power from solar PV & \multicolumn{2}{|l|}{----- } & \multicolumn{2}{|l|}{1.76} \\
\hline Active power demand & \multicolumn{2}{|l|}{$86.961 \mathrm{MW}$} & \multicolumn{2}{|l|}{$86.961 \mathrm{MW}$} \\
\hline Reactive power demand & \multicolumn{2}{|l|}{ 52.419 MVAr } & \multicolumn{2}{|l|}{ 52.419 MVAr } \\
\hline Active power loss & \multicolumn{2}{|l|}{$3.464 \mathrm{MW}$} & \multicolumn{2}{|l|}{3.015} \\
\hline Reactive power loss & \multicolumn{2}{|l|}{$0.892 \mathrm{MVAr}$} & \multicolumn{2}{|l|}{0.826} \\
\hline Total operating cost (MU/MWh) & \multicolumn{2}{|l|}{ 1958.351 } & \multicolumn{2}{|l|}{1926.247} \\
\hline Opened lines between the buses & \multicolumn{2}{|l|}{$5-9,6-11,8-13$} & \multicolumn{2}{|l|}{$5-9,6-11,8-13$} \\
\hline Minimum voltage in phase R (in p.u.) & \multicolumn{2}{|l|}{0.9495 at bus 14} & \multicolumn{2}{|l|}{0.9657 at bus 13} \\
\hline Minimum voltage in phase $\mathrm{Y}$ (in p.u.) & \multicolumn{2}{|l|}{0.9488 at bus 14} & \multicolumn{2}{|l|}{0.9641 at bus 13} \\
\hline Minimum voltage in phase B (in p.u.) & \multicolumn{2}{|l|}{0.9474 at bus 14} & \multicolumn{2}{|l|}{0.9628 at bus 13} \\
\hline
\end{tabular}

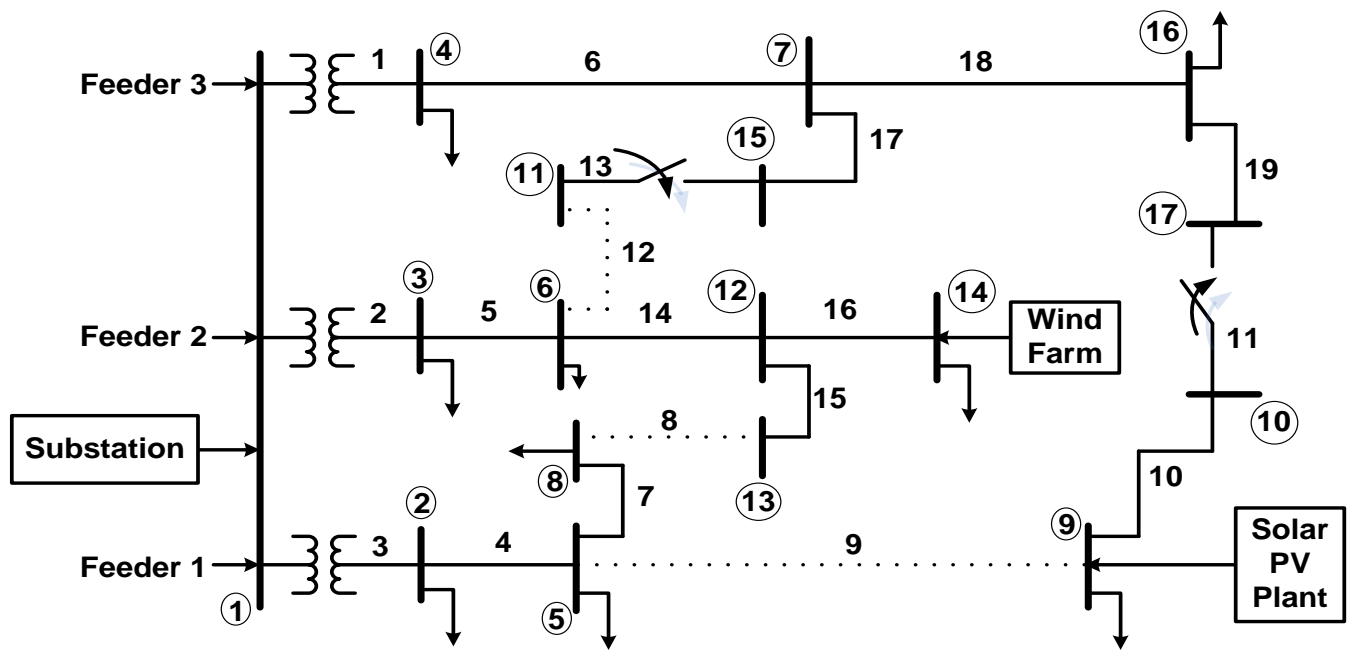

Fig. 8. SLD of 17 Bus System after the FRC for Case Study 2.

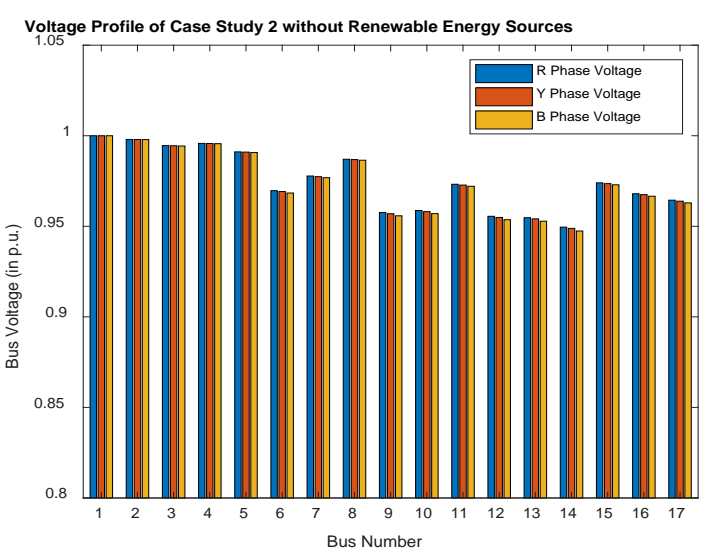

Fig. 9. Voltage Profile of Case Study 2 without Renewable Power Generation. 


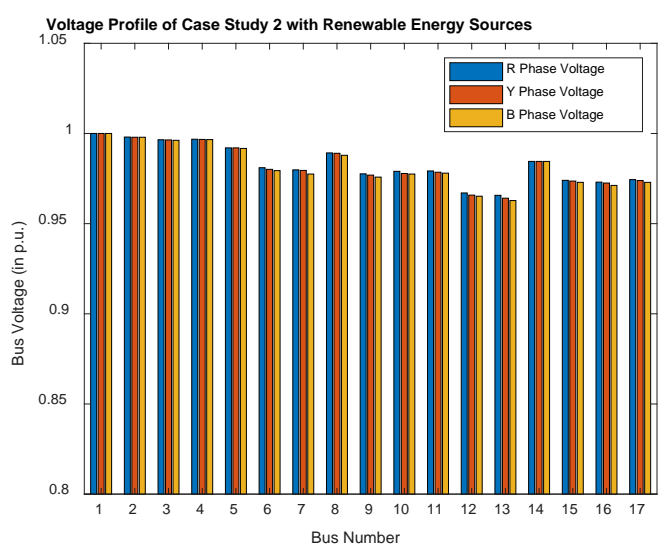

Fig. 10. Voltage Profile of Case Study 2 with Renewable Power Generation.

TABLE IV. NOMENCLATURE

\begin{tabular}{|c|c|}
\hline Symbol & Description \\
\hline$V_{p}, V_{s}$ & 3-phase bus voltages at the primary side and secondary side of the 3-transformer \\
\hline$T_{A}$ & Ambient temperature $\left({ }^{\circ} \mathrm{C}\right)$ \\
\hline$v_{\text {cin }}$ & Cut-in wind speed \\
\hline$y_{t}$ & Per unit transformer leakage admittance \\
\hline$P_{W}^{r}$ & Rated power of wind energy generator (WEG) \\
\hline$N_{O T}$ & The nominal operating temperature of the cell $\left({ }^{\circ} \mathrm{C}\right)$ \\
\hline$v$ & Wind speed at a particular time and location \\
\hline$v_{\text {cout }}$ & Cut-out wind speed \\
\hline$G$ & Solar irradiance $\left(\mathrm{W} / \mathrm{m}^{2}\right)$ \\
\hline$\omega$ & Weight factor $(0<\omega<\infty)$ \\
\hline$T_{c}$ & Solar PV cell temperature $\left({ }^{\circ} \mathrm{C}\right)$ \\
\hline$v_{r}$ & Rated wind speed \\
\hline$K_{I}$ & Temperature coefficient of current $\left(\mathrm{V} /{ }^{\circ} \mathrm{C}\right)$ \\
\hline$V_{M P P}$ & Maximum power point voltage $(\mathrm{V})$ \\
\hline$I_{M P P}$ & Maximum power point current (A) \\
\hline$I_{p}, I_{s}$ & 3-phase bus injection currents at the primary side and secondary side of the 3-transformer \\
\hline$F F$ & Fill factor \\
\hline$N_{F}$ & Number of feeders \\
\hline$V_{O C}$ & Open circuit voltage (V) \\
\hline$C_{i}$ & Cost coefficient of $i^{\text {th }}$ feeder \\
\hline$P_{i}$ & Active power injection from the $i^{\text {th }}$ feeder \\
\hline$P_{W j}$ & Active power output from $j^{\text {th }}$ wind generator \\
\hline$P_{P V k}$ & Active power output from $k^{\text {th }}$ solar PV unit \\
\hline$N_{B}$ & Number of buses \\
\hline$P_{i}^{\max }$ & Maximum power injected at $i^{\text {th }}$ feeder \\
\hline$I_{S C}$ & Short circuit current (A) \\
\hline$V_{b}$ & The magnitude of voltage at $b^{\text {th }}$ bus \\
\hline$V_{b}^{\min }, V_{b}^{\max }$ & Minimum and maximum bus voltages at $b^{\text {th }}$ bus \\
\hline$I_{l}$ & Current in $l^{\text {th }}$ line \\
\hline$N_{l}$ & Number of lines \\
\hline$I_{l}^{\max }$ & Maximum allowable branch current \\
\hline$N_{P V}$ & Number of solar PV modules in a solar array \\
\hline$Y_{T}$ & Nodal admittance matrix \\
\hline$K_{V}$ & Temperature coefficient of voltage $\left(\mathrm{A} /{ }^{\circ} \mathrm{C}\right)$ \\
\hline
\end{tabular}




\section{CONCLUSIONS}

This paper proposes the FRC approach for the balanced and unbalanced distribution system for the total operating cost (TOC) minimization. Generally, the distribution systems are unbalanced, and hence the 3-phase representation is required. The importance and the effect of the 3-phase transformer model and its effect on system performance have been high lighted in this paper. In this work, wind and solar photovoltaic (PV) units are selected as distributed energy resources (DERs) and they are considered in the proposed FRC approach. The amount of power generation from wind and solar PV units is determined by using probability analysis. The proposed approach has been solved by using the ant lion optimization (ALO) algorithm. The optimal topology for an unbalanced system is different from that of a balanced system. However, the topology is the same for the cases with and without RESs. And also, the TOC obtained with RESs is less than the TOC obtained without the RESs. Solving the proposed FRC problem including the battery energy storage units and electric vehicle charging loads is the scope for future research work.

\section{ACKNOWLEDGMENT}

This research work was funded by "Woosong University's Academic Research Funding - 2021”.

\section{REFERENCES}

[1] K.S. Kumar, S. Naveen, "Power system reconfiguration and loss minimization for a distribution systems using Catfish PSO algorithm”, Frontiers in Energy, vol. 8, pp. 434-442, 2014.

[2] A.V.S. Reddy, M.D. Reddy, M.S.K. Reddy, "Network Reconfiguration of Primary Distribution System Using GWO Algorithm”, International journal of electrical and computer engineering, vol. 7, no. 6, pp. 32263234, Dec. 2017.

[3] Z. Ye, C. Chen, B. Chen, K. Wu, "Resilient Service Restoration for Unbalanced Distribution Systems With Distributed Energy Resources by Leveraging Mobile Generators", IEEE Transactions on Industrial Informatics, vol. 17, no. 2, pp. 1386-1396, Feb. 2021.

[4] F. Ding, K.A. Loparo, "Feeder Reconfiguration for Unbalanced Distribution Systems with Distributed Generation: A Hierarchical Decentralized Approach,” IEEE Transactions on Power Systems, vol. 31, no. 2, pp. 1633-1642, Mar. 2016.

[5] Y. Du, X. Lu, H. Tu, J. Wang, S. Lukic, "Dynamic Microgrids With Self-Organized Grid-Forming Inverters in Unbalanced Distribution Feeders”, IEEE Journal of Emerging and Selected Topics in Power Electronics, vol. 8, no. 2, pp. 1097-1107, June 2020.

[6] M. Khederzadeh, S. Zandi, "Enhancement of Distribution System Restoration Capability in Single/Multiple Faults by Using Microgrids as a Resiliency Resource”, IEEE Systems Journal, vol. 13, no. 2, pp. 17961803, June 2019.

[7] T.T. The, D.V. Ngoc, N.T. Anh, "Distribution Network Reconfiguration for Power Loss Reduction and Voltage Profile Improvement Using Chaotic Stochastic Fractal Search Algorithm”, Complexity, vol. 2020, pp. 1-15, 2020.

[8] J.B.V. Subrahmanyam, C. Radhakrishna, "A Simple Method for Feeder Reconfiguration of Balanced and Unbalanced Distribution Systems for Loss Minimization”, Electric Power Components and Systems, vol. 38, no. 1, pp. 72-84, 2009.

[9] H. Lotfi, R. Ghazi, M.B. Naghibi-Sistani, "Multi-objective dynamic distribution feeder reconfiguration along with capacitor allocation using a new hybrid evolutionary algorithm", Energy Systems, no. 3, 2020.

[10] M.A. Abdelkader, Z.H. Osman, M.A. Elshahed, "New analytical approach for simultaneous feeder reconfiguration and DG hosting allocation in radial distribution networks," Ain Shams Engineering Journal, 2020.
[11] Md.R. Islam, H. Lu, M.J. Hossain, L. Li, "Mitigating unbalance using distributed network reconfiguration techniques in distributed power generation grids with services for electric vehicles: A review,” Journal of Cleaner Production, vol. 239, 2019.

[12] H.F. Zhai, M. Yang, B. Chen, N. Kang, "Dynamic reconfiguration of three-phase unbalanced distribution networks," International Journal of Electrical Power \& Energy Systems, vol. 99, pp. 1-10, 2018.

[13] S.A. Taher, M.H. Karimi, "Optimal reconfiguration and DG allocation in balanced and unbalanced distribution systems," Ain Shams Engineering Journal, vol. 5, no. 3, pp. 735-749, 2014.

[14] S.S. Fazlhashemi, M. Sedighizadeh, M.E. Khodayar, "Day-ahead energy management and feeder reconfiguration for microgrids with CCHP and energy storage systems”, Journal of Energy Storage, vol. 29, 2020.

[15] M. Sedighizadeh, R.V. Doyran, A. Rezazadeh, "Optimal simultaneous allocation of passive filters and distributed generations as well as feeder reconfiguration to improve power quality and reliability in microgrids," Journal of Cleaner Production, vol. 265, 2020.

[16] A. Azizivahed, H. Narimani, M. Fathi, E. Naderi, H.R. Safarpour, M.R. Narimani, "Multi-objective dynamic distribution feeder reconfiguration in automated distribution systems," Energy, vol. 147, pp. 896-914, 2018.

[17] G.K.V. Raju, P.R. Bijwe, "Efficient reconfiguration of balanced and unbalanced distribution systems for loss minimization," IET Generation. Transmission and Distribution, vol. 2, no. 1, pp. 7-12, 2008.

[18] G.K.V. Raju, P.R. Bijwe, "An Efficient Algorithm for Minimum Loss Reconfiguration of Distribution System Based on Sensitivity and Heuristics," IEEE Transactions Power Systems, vol.23, no.3, pp. Aug. 2008.

[19] S.S. Reddy, P.R. Bijwe, A.R. Abhyankar, "Optimum day-ahead clearing of energy and reserve markets with wind power generation using anticipated real-time adjustment costs," International Journal of Electrical Power \& Energy Systems, vol. 71, pp. 242-253, 2015.

[20] S.S. Reddy, "Optimal scheduling of thermal-wind-solar power system with storage,” Renewable Energy, vol. 101, pp. 1357-1368, 2017.

[21] S.S. Reddy, J.A. Momoh, "Realistic and Transparent Optimum Scheduling Strategy for Hybrid Power System,” IEEE Transactions on Smart Grid, vol. 6, no. 6, pp. 3114-3125, Nov. 2015.

[22] M. Kaur, S. Ghosh, "Network reconfiguration of unbalanced distribution networks using fuzzy-firefly algorithm," Applied Soft Computing, vol. 49, pp. 868-886, 2016.

[23] S. Ghasemi, "Balanced and unbalanced distribution networks reconfiguration considering reliability indices," Ain Shams Engineering Journal, vol. 9, no. 4, pp. 1567-1579, 2018.

[24] I.G. Guimarães, D.P. Bernardon, V.J. Garcia, M. Schmitz, L.L. Pfitscher, "A decomposition heuristic algorithm for dynamic reconfiguration after contingency situations in distribution systems considering island operations,” Electric Power Systems Research, vol. 192, 2021.

[25] Sang-Bong Rhee, Yu-Jeong Lee, Seok-Ku You, Kyu-Ho Kim, "Network Reconfiguration Using Chaos Search Method in Unbalanced Distribution Systems," IFAC Proceedings Volumes, vol. 36, no. 20, pp. 803-807, 2003.

[26] A. Swarnkar, N. Gupta, K.R. Niazi, “Adapted ant colony optimization for efficient reconfiguration of balanced and unbalanced distribution systems for loss minimization,” Swarm and Evolutionary Computation, vol. 1, no. 3, pp. 129-137, 2011.

[27] C.H.N.R. Barbosa, M.H.S. Mendes, J.A. Vasconcelos, "Robust feeder reconfiguration in radial distribution networks," International Journal of Electrical Power \& Energy Systems, vol. 54, pp. 619-630, 2014.

[28] G. Mahendran, C. Govindaraju, "Flower pollination algorithm for distribution system phase balancing considering variable demand," Microprocessors and Microsystems, vol. 74, 2020.

[29] M. Wang, A.A. Heidari, M. Chen, H. Chen, X. Zhao, X. Cai, "Exploratory differential ant lion-based optimization", Expert Systems with Applications, vol. 159, 2020.

[30] J. Wanga, P. Dua, H. Lub, W. Yanga, T. Niu, “An improved grey model optimized by multi-objective ant lion optimization algorithm for annual electricity consumption forecasting”, Applied Soft Computing, vol. 72, pp. 321-337, 2018. 